\title{
Frequency Diagnostics of Insulating System of Power Transformers
}

\author{
Miroslav Gutten* (Professor, University of Zilina, Zilina, Slovakia), \\ Daniel Korenciak (Assoc. Professor, University of Zilina, Zilina, Slovakia), \\ Peter Brncal (Ph. D. student, University of Zilina, Zilina, Slovakia), \\ Roman Jarina (Assoc. Professor, University of Zilina, Zilina, Slovakia)
}

\begin{abstract}
The paper presents experimental diagnostics of the oil-paper insulating system of power transformers using progressive frequency method. The first part of the paper deals with the basic information about diagnostics of power oil transformers. The second part of the paper deals with the use of frequency domain spectroscopy (FDS) for power oil transformers. This method is used in the analysis of insulating condition of power transformer with the system of oil-paper. It was found that the results of these tests are highly influenced by the operating temperature during the experimental measurement. Moisture and conductivity between the insulating transformer paper and oil in an insulating system are highly dependent on the temperature. In the other part, the paper presents experimental results of the diagnostic measurement for a real traction oil transformer at different operating temperatures and states (with oil and without). Finally, the paper presents comparative measurement among several autotransformers with the same power. In experimental measurements, the correlation between the measured values and the operational aspects of the individual oil autotransformers are shown.
\end{abstract}

Keywords - Conductivity; Moisture; Power transformers; Spectroscopy.

\section{INTRODUCTION}

The development of diagnostics, maintenance, and control, and their analysis by mathematic calculations is an important technical sphere of the national economics. This sphere also includes high-voltage transformers; their correct functioning has a positive effect on the trouble-free supply of electricity and heat for households and industries. The significance of diagnostics at the premises of strategic significance is determined not only by the economic aspect, but also by considerations of faultless operation and safety, i.e. reliability of technical devices in the power electrical engineering.

It is therefore necessary, in the absence of scientific and research potential in a transfer and distribution organizations (e.g. heating plants, power plants), to achieve the objectives of the proposed activities, i.e. careful analysis of undesirable impacts on the condition of devices, proposal of measurements and their verification, and proposal of new diagnostic and

\footnotetext{
* Corresponding author.

E-mail: miroslav.gutten@fel.uniza.sk
}

measuring procedures for improving reliability of high-voltage transformers [1].

The quality of the insulating parts of the transformer in the oil-paper fabrication can deteriorate over a period of several years. If this element of the equipment is not checked regularly, the insulation parts will be damaged, which in turn will lead to a dangerous destruction of the entire transformer. It is therefore necessary to properly diagnose the dielectric properties of this device. The increase in moisture and formation of water in the oil transformer results in the deterioration of the transformer's operating condition and consequently presents a risk of serious failure (for example, winding failure and feed, aging of insulation barriers and paper, deterioration of oil cooling and insulation).

As the humidity increases in the insulating parts of the transformer, the quality of the insulating paper deteriorates, which can lead to an increase in partial discharge. Partial discharges can affect the temperature rise in the entire transformer. This temperature rise can become uncontrollable and the device becomes dangerous due to possible fire.

It is necessary to know the condition of the transformer insulation between dielectric elements and the insulating properties in the operating state.

The first approach, called recovery voltage method (RVM Fig. 1), is already well-known. Two newer methods, polarization and depolarization currents (PDC) and frequency domain spectroscopy (FDS), have demonstrated their suitability for diagnostics of transformers and are now frequently used [2].

The advantage of these methods is that it is possible to detect moisture in the paper insulation and determine conductivity in the oil of power transformers

Transformer oil analysis is part of the overall diagnostics of the dielectric subsystem of each piece of electrical equipment filled with oil. This diagnostic includes tests and measurements to verify the insulation and cooling properties of the oil. It acts as an interface for the transfer of such components as moisture, air, aging products, mechanical impurities and the like.

Electrical and thermal stresses transform dielectric oil into different gases. These gases indicate developing damage to the electrical machine or apparatus. Their timely indication helps early intervention and prevention of the costly removal of large- 
scale damage. The gas formed dissolves in the insulating oil in a quantity dependent on the type of gas, the quality of the insulating oil, the viscosity, temperature and pressure [3].

The failure in the transformer can develop slowly or rapidly depending on failure type. Therefore, it is advisable to monitor the operation of the transformer in real time to keep track of what is going on inside. The easiest way to follow this medium is by transforming the transformer oil into several gases [3].

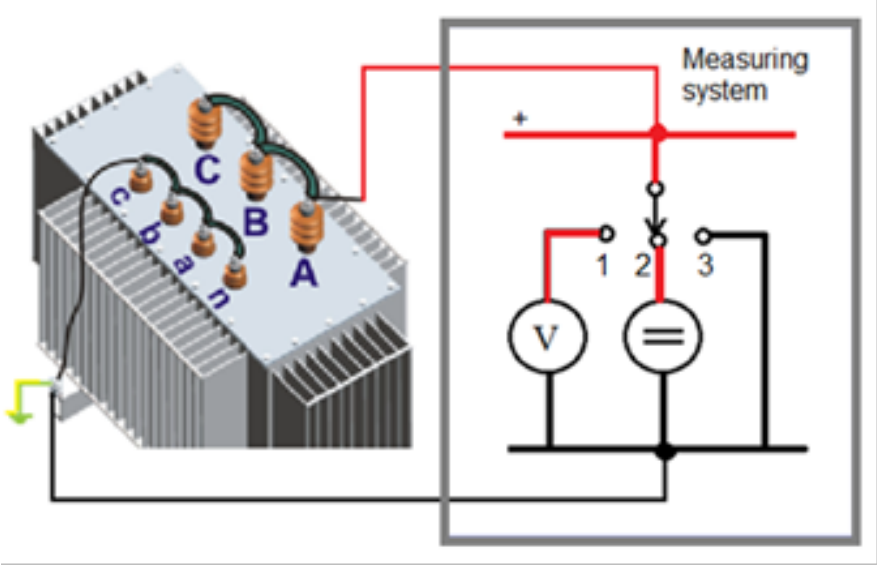

Fig. 1. Principal scheme of the RVM method.

\section{Diagnostics Methods AND ANALYSIS OF TRANSFORMERS}

The important problem of the existing energy companies is that the data on a large number of measured parameters obtained by diagnostic measurements are not adequately studied. Identification of the condition of power transformers, mainly in terms of their residual lifetime, is the main technical problem. The fault may occur at an unpredictable moment of transformer operation. The fault may result in the power breakdown for a short or long time. It is necessary to analyse the measured values of transformer parameters for the purposes of monitoring. Therefore, the analysis will be necessarily based on the knowledge about the exposure to adverse influences of energetic phenomena, for example, short circuit currents, overcurrent or overvoltage. Reaching these objectives by using suitable diagnostics may help identify the adverse effects of short circuit and propose new measuring procedures. Moreover, it is possible to identify the forthcoming failure of the transformer. It is possible to implement some measures in advance (e.g. repair of single parts of the transformer) [4].

Considering the adverse effects of short-circuit forces, which damage coils, magnetic construction and taps, the following analyses are to be realized on the disconnected distribution transformers:

- analysis of basic insulation parameters (resistances, permittivity, capacity and loss factor);

- measurement of the parameters in time dependence (polarization and depolarization DC currents (Fig. 2) and return voltages (PDC and RVM method);

- measurement of transformer parameters in frequency dependence by Sweep Frequency Response Analysis (SFRA) method;

- measurement of winding parameters of power transformer at short-circuit state;
- measurement of breakdown oil parameters of the transformer;

- analysis of time response of transformer windings by impact test using the high-voltage impulse source;

- chromatographic analysis of the quality of transformer oils;

- analysis of insulating parameters by frequency dielectric spectroscopy (FDS) method;

- combination of measuring methods according to the proposed diagnostic procedures [5].

The use of monitoring diagnostic methods and measurement procedures is useful for transformers connected to electric power. They include thermography and noise analysis and monitoring of basic insulating and mechanical parameters of transformers. Adverse electromagnetic interference from the transformer may cause mechanical change in the coil depending on the result of shift or inter-turn short circuit of the winding.

Therefore, it is possible to use the following measurements of connected transformers that will be realized using experimental apparatuses [6], [7]:

- thermography analysis;

- analysis of electromagnetic radiation from transformers;

- measurement of acoustic emission generated at discharges, determination of energy magnitude, speed of exchange between energy of discharge and surrounding oil, and localization of faulty state.

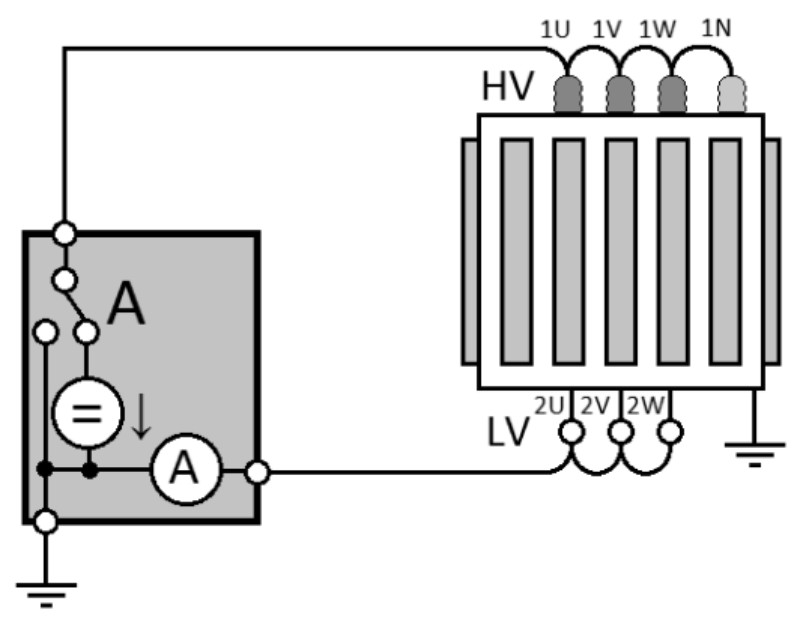

Fig. 2. Principles of an easy PDC system.

Due to recent advances in massive multi-sensor analysis, phased-array signal processing and high-speed computing hardware technologies, acoustic emission (AE) based analysis has become an important diagnostic tool in manufacturing, machine building and electrotechnical industry [9].

Acoustic analysis is also increasingly seen as an interesting alternative approach for monitoring and diagnostics of faults in power transformers.

Vibrations in the core and winding are the main sources of acoustic emission from a transformer [10], [11]. The vibrations are mostly caused by the following reason - the loosening of winding clamping may cause coil vibrations. Similarly, loosening of core clamping may cause core vibration. Other 
sources of $\mathrm{AE}$ in the core include such phenomena as magnetostriction or magnetoacoustic emission by the Barkhausen effect [10], [11]. The vibrations in the core and coil produce AE with maximal energy in the audible frequency range. Such AE mainly has a tonal character with the fundamental frequency related to the frequency of electrical current. Due to nonlinear dependence between electromagnetic forces and mechanical vibrations, fundamental frequency is usually twice the frequency of the current, i.e. $100 \mathrm{~Hz}$, and spectrum of the AE is rich in higher harmonics. In addition, the noise generated by magnetoacoustic emission causes random high-frequency fluctuations in the acoustic waveform [11].

Partial discharges either in the insulating bushings or winding insulation can be another source of AE in the insulating system; however, partial discharges generate $\mathrm{AE}$ in the ultrasound range with the maximal level above $100 \mathrm{kHz}$ [12], [13].

Such AE generated by a transformer carries information about its operation load and health condition. However, direct AE measurements for a purpose of transformer diagnostics have some limitations. Since the core and windings of the highpower transformers are placed in a tank filled with oil, only the tank vibrations are readily available for acoustic monitoring of the power transformers in operation [14]. Despite this fact, several research works have reported successful acoustic diagnostics of transformers. Some works have focused on monitoring of partial discharge [10], [12], [13].

It has been proven in [15], [16] and others that measurements of tank vibrations can be used for detecting deformations and monitoring of operational load of transformer windings. The tank vibrations are usually measured by accelerometers and vibration sensors placed on the tank.

\section{DIAGNOSTIC INSULATING ANALYSIS OF TRANSFORMERS BY FDS METHOD}

Previous research works on condition diagnostics of dialectical insulation have indicated that the frequency domain spectroscopy can the most effectively estimate deterioration in insulation of oil-paper in power transformers. Since especially the low frequencies (to $0.1 \mathrm{~Hz}$ ) reflect moisture concentration, their measurement is of outmost importance for reliable data analysis [9].

Special focus is made on comparison of the currently available dielectric spectroscopy methods with traditional measurement techniques like dielectric dissipation factor $(\operatorname{tg} \delta)$ tests at power frequency and $0.1 \mathrm{~Hz}$, dielectric adsorption ratio and the polarization index [18]. Applying a sinus frequency sweep in the range from $0.0005 \mathrm{~Hz}$ to $10 \mathrm{kHz}$ is used to measure the dielectric responses depending on the quality of transformer insulation [19].

Dielectric response of the whole insulation system in the transformer depends on different factors, i.e. on the properties of impregnated paper and pressboard, the properties of oil, and the geometrical arrangement of the system components. The correct evaluation of the measured data involves mathematical modelling, which requires the knowledge on the variation of the oil and paper/pressboard properties depending on temperature and moisture. In addition, information about design of insulation system is required, i.e. the relative amounts of pressboard barriers and spacers in relation to the amount of oil. For power transformers insulated oil-paper, the dielectric response consists of three components: the response of the cellulose insulation (paper, pressboard), the response of the oil and the interfacial polarization effect. Moisture, temperature, insulation geometry, oil conductivity and conductive aging byproducts influence the dielectric response [20], [21].

Fig. 3 presents the dissipation factor of pressboard having $1 \%$ moisture content and oil together with the interfacial polarization effect (insulation geometry). The frequency range of $1000-10 \mathrm{~Hz}$ is dominated by the cellulose insulation, however, also the measurement cables and the connection technique influence this region. Oil conductivity causes the steep slope at $1-0.01 \mathrm{~Hz}$. Dissolved conductive aging byproducts, soot and high molecular weight acids increase oil conductivity and thus influence this area. The interfacial polarization (insulation geometry, ratio of oil to pressboard) determines the local maximum at $0.003 \mathrm{~Hz}$ [17].

The higher the ratio of oil to pressboard, the more dominating this effect is. Finally, the properties of cellulose appear again at the frequencies below $0.0005 \mathrm{~Hz}$, here reflecting moisture, the manufacturing process and low molecular weight acids. The frequency limits correspond to Fig. 3, but will vary in a wide range with moisture, oil conductivity, insulation geometry, temperature and amount of conductive aging by-products. Moisture particularly increases the losses in the low frequency range of the dielectric response of pressboard. Thus, the point of inflexion on the left-hand side of the area dominated by insulation geometry is required for a reliable moisture determination [18], [22].

The method of FDS is mainly used for oil-paper insulation; it can also be used for dry transformers or high-voltage equipment with ferrofluid in magnetic field [23].

This experimental analysis aims at determination of a new set of diagnostic and measuring techniques for the analysis of the condition of selected type of oil filled power transformers [24], [25].

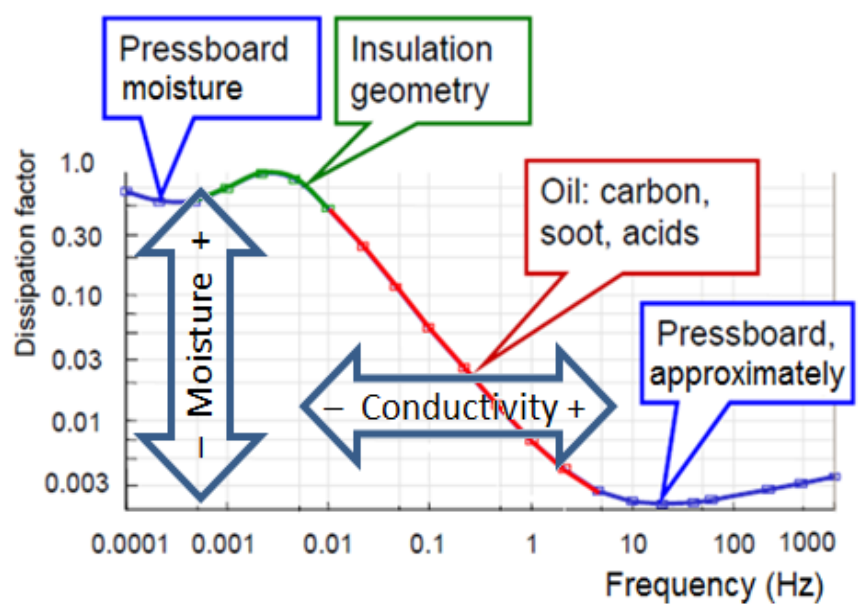

Fig. 3. Analysis of insulating transformer properties by the curve of FDS method. 


\section{EXPERIMENTAL MEASUREMENT}

\section{A. Frequency Diagnostics of the Transformer at Different Conditions}

An experimental measurement was conducted on traction single-phase transformer $110 / 27 \mathrm{kV}$, which was installed in high-voltage traction substation, for moisture analysis by dielectric spectroscopy. Measurement was conducted at temperature $+15^{\circ} \mathrm{C}$ with transformer oil and $-5{ }^{\circ} \mathrm{C}$ without oil.

Apparatus MEGGER IDAX-350 was used for measuring with the connection according to Fig. 4, which works on the principle of dielectric spectroscopy (FDS method) by measuring the percentage loss factor, capacities and permittivity at the frequency of $1 \mathrm{kHz}$ up to $0.0001 \mathrm{~Hz}$ in the sinusoidal power supply $140 \mathrm{~V}_{\mathrm{ef}}[14]$.

At the first measurement with oil at $+15^{\circ} \mathrm{C}$, the total isolation state of the transformer at $20^{\circ} \mathrm{C} / 50 \mathrm{~Hz}$ was considered "good state" according to percentage dissipation factor $(\% \operatorname{tg} \delta=0.25)$ and paper moisture was considered "good state" $(1.95 \%)$ by the rating graphs of measuring apparatus 350 IDAX (Fig. 4).

At the second measurement without oil at $-5{ }^{\circ} \mathrm{C}$ in comparison, the total isolation state of the transformer at $20{ }^{\circ} \mathrm{C} / 50 \mathrm{~Hz}$ was better according to $\% \operatorname{tg} \delta=0.22$ and paper moisture was better too $(1.50 \%)$. The capacity of insulating system was significantly lower (Fig. 5), because transformer oil makes a significant part of the whole transformer insulating system.

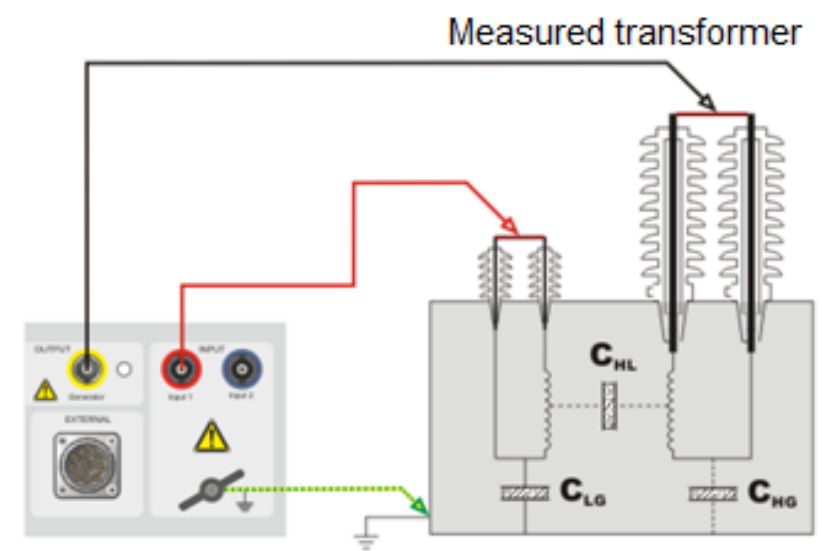

\section{System Megger IDAX}

Fig. 4. Connection of the system MEGGER IDAX-350 to the measured single traction transformer $110 / 27 \mathrm{kV}$.

According to Fig. 5, lower temperature causes shift of the curve to lower frequencies (direction to the left). This shift was the proof of the theoretical graph in Fig. 3. Draining of the oil before the second measurement was another impact, due to that conductivity of transformer oil was reduced to zero (conductivity direction to the left according to Fig. 3).

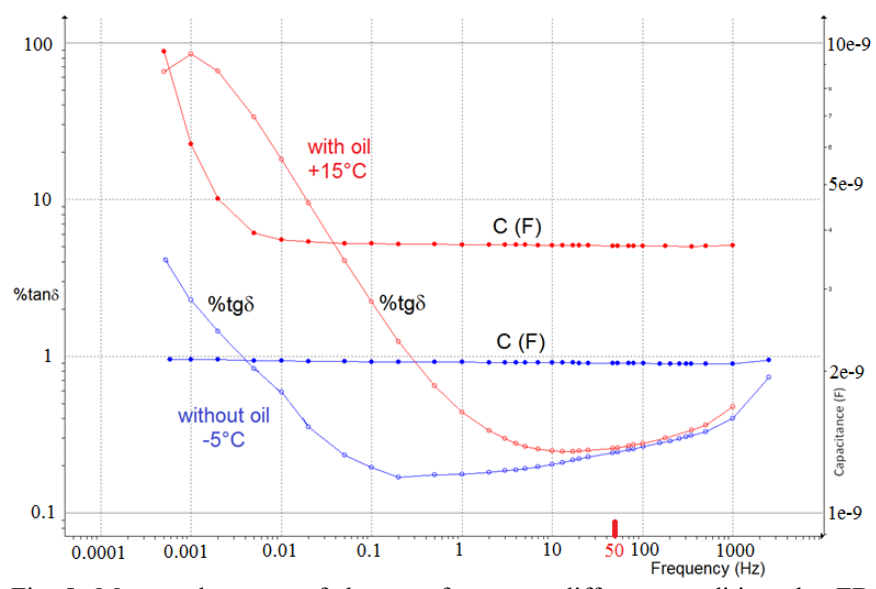

Fig. 5. Measured curves of the transformer at different conditions by FDS method and apparatus IDAX-350.

As measurement is performed at very low currents, it is necessary to consistently link all connections according to Fig. 4. Since the device separately distinguishes the measurement of individual capacities, it is necessary to thoroughly clean the location for connection of the ground conductor of the device. Poor connection results in errors in current measurements (and then calculated value of percentage loss factor $-\% \operatorname{tg} \delta$ ) at frequencies above $200 \mathrm{~Hz}$ (Fig. 6).

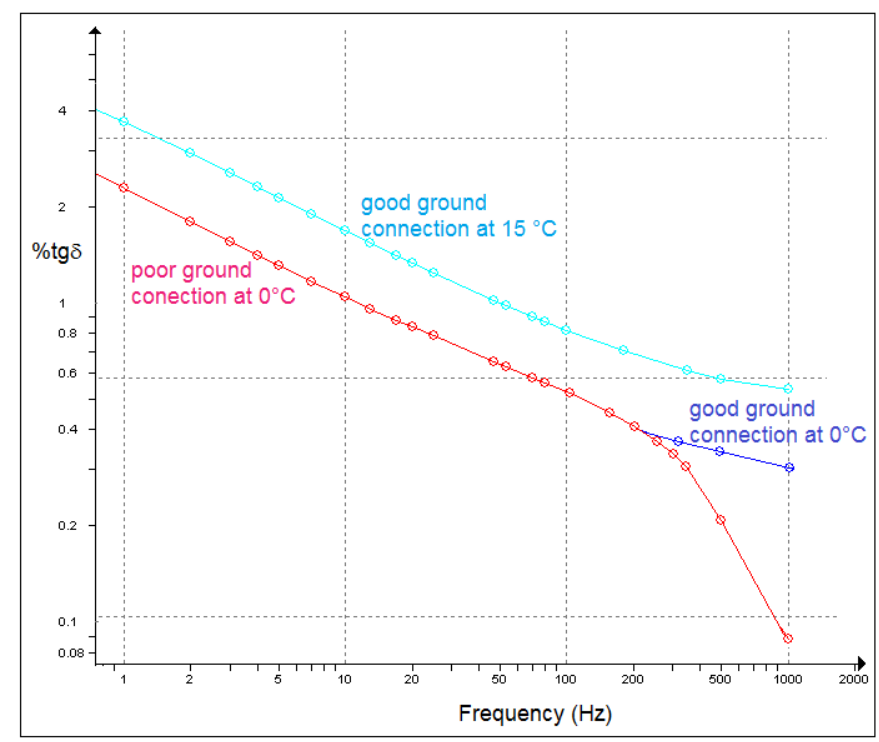

Fig. 6. Measured curves of the transformer at different conditions and poor/good ground by FDS method and apparatus IDAX-350.

\section{B. Comparison of Insulating State of Several Transformers}

In this part of the paper, experimental measurement of singlephase oil autotransformers 231/121/10.6 kV, labelled $\mathrm{R}, \mathrm{S}, \mathrm{T}$, $\mathrm{Q}$, which are installed in power substation, is described. Frequency method FDS was used for analysis of paper moisture, conductivity in oil and the total state of insulation of autotransformers.

Transformers were disconnected from the power source and measured at the ambient temperature of $16^{\circ} \mathrm{C}$. All calculations at $20{ }^{\circ} \mathrm{C}$ for the loss factor and $25^{\circ} \mathrm{C}$ for the conductivity of the transformer oil were performed by the instrument MEGGER IDAX-350. 
Apparatus MEGGER IDAX-350 with the connection to autotransformer according to Fig. 7 was used for the measurement, which works on the principle of frequency domain spectroscopy (FDS method). Using this method, the following parameters were measured - the percentage loss factor, capacities and permittivity depending on the frequency of $10 \mathrm{kHz}$ up to $1 \mathrm{MHz}$ in the sinusoidal power supply $140 \mathrm{~V}_{\text {ef }}$.

According to Fig. 7, measurement includes transformer capacity CHT between very high-voltage (VHV) and highvoltage (HV) windings and tertiary winding and capacities CTG and CHG between windings and transformer ground.

The measured real capacities and dissipation factor in frequency dependence of measured autotransformer 231/121/10.6 kV, designated R, S, T, Q, are shown in Fig. 8 and Fig. 9.

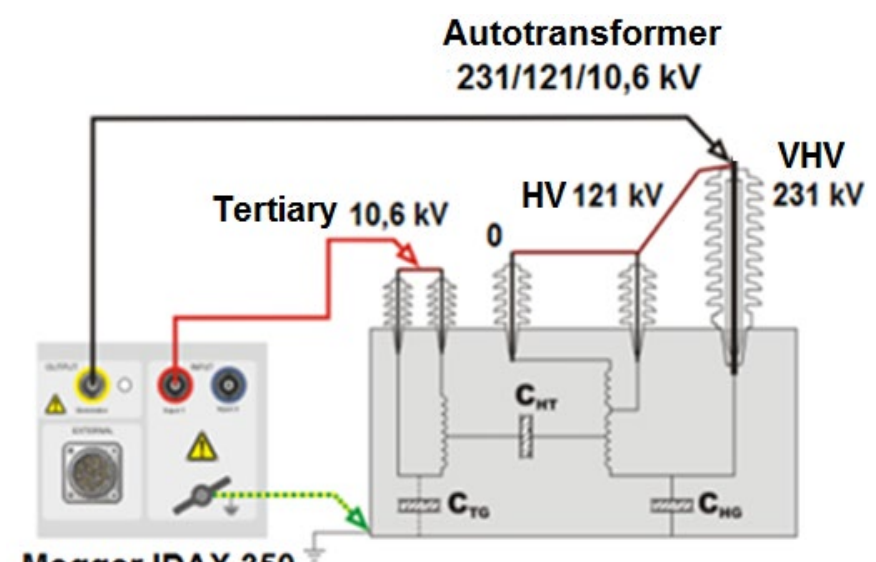

\section{Megger IDAX 350}

Fig. 7. Connection of the instrument MEGGER IDAX-350 to the measured autotransformer 231/121/10.6 kV.

Evaluation and analysis measurement of the individual autotransformers R, S, T, Q were performed by apparatus IDAX according to the rating table (Table I).

The total isolation state at $20{ }^{\circ} \mathrm{C} / 50 \mathrm{~Hz}$ was "good state" according to the rating table of the percentage dissipation factor $(\operatorname{tg} \delta \%)$ and analysis of the measured curves in Fig. 8 and Fig. 9.

TABLE I

BASIC ANALYSES BY INSTRUMENT IDAX-350

\begin{tabular}{|c|c|c|}
\hline \multicolumn{3}{|c|}{ Analysis of Transformer Status Results by IDAX } \\
\hline $\operatorname{tg} \delta \%$ at $50 \mathrm{~Hz} / 20^{\circ} \mathrm{C}$ & $\begin{array}{l}\text { Moisture in paper } \\
(\%)\end{array}$ & $\begin{array}{l}\text { Conductivity of the oil } \\
\text { at } 25^{\circ} \mathrm{C}(\mathrm{pS} / \mathrm{m})\end{array}$ \\
\hline $\begin{array}{l}<0.30 \% \\
\text { As new }\end{array}$ & $\begin{array}{l}<1.0 \% \\
\text { As new }\end{array}$ & $\begin{array}{l}<0.37 \mathrm{pS} / \mathrm{m} \\
\text { As new }\end{array}$ \\
\hline $\begin{array}{l}0.30-0.50 \% \\
\text { Good }\end{array}$ & $\begin{array}{l}1.0-2.0 \% \\
\text { Dry }\end{array}$ & $\begin{array}{l}<0.37-3.7 \mathrm{pS} / \mathrm{m} \\
\text { Good }\end{array}$ \\
\hline $\begin{array}{l}0.50-1.0 \% \\
\text { Deteriorated }\end{array}$ & $\begin{array}{l}2.0-3.0 \% \\
\text { Moderately wet }\end{array}$ & $\begin{array}{l}3.7-37 \mathrm{pS} / \mathrm{m} \\
\text { Service aged }\end{array}$ \\
\hline $\begin{array}{l}>1.0 \% \\
\text { Investigate }\end{array}$ & $\begin{array}{l}>3.0 \% \\
\text { Wet }\end{array}$ & $\begin{array}{l}>37 \mathrm{pS} / \mathrm{m} \\
\text { Deteriorated }\end{array}$ \\
\hline
\end{tabular}

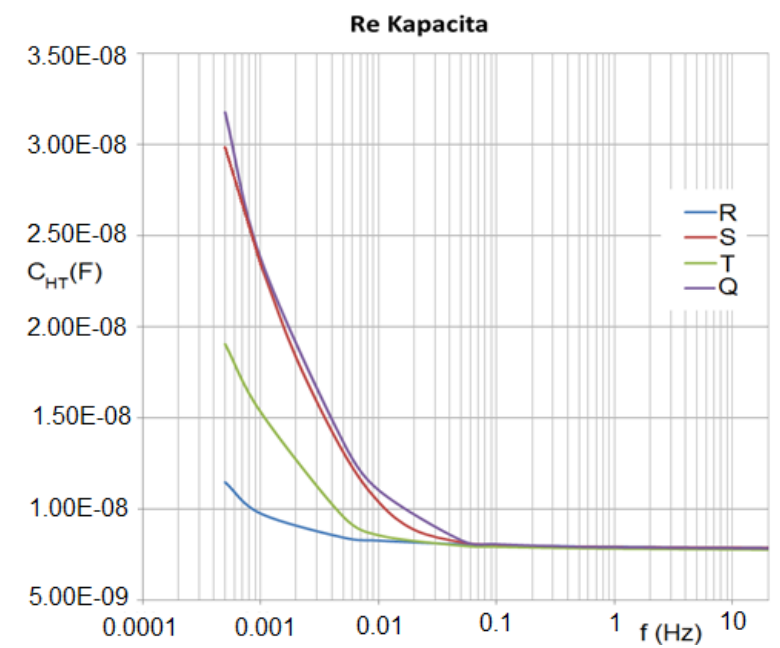

Fig. 8. Comparison of the measured autotransformers R, S, T, Q according to the real capacities for connection high-voltage winding $-\operatorname{tank} C_{\mathrm{HT}}$.

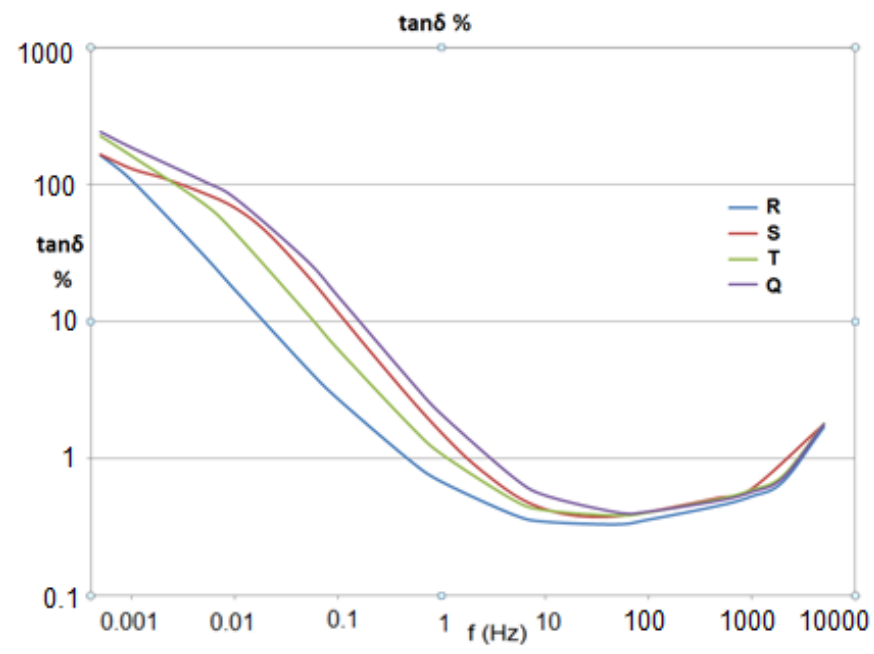

Fig. 9. Comparison of the measured autotransformers R, S, T, Q according to the percentage dissipation factor $(\operatorname{tg} \delta \%$ ) depending on frequency.

\section{Discussion of the Measured Data}

Comparing these autotransformers according to Table II, the best (lowest) value of the loss factor $\operatorname{tg} \delta \%$ state was demonstrated by autotransformer $\mathrm{R}$ with a value of $0.323 \%$, transformers $\mathrm{S}$ and $\mathrm{T}$ had approximately the same value in the range $0.380-0.381 \%$. Transformer Q showed a slightly higher value loss factor $\operatorname{tg} \delta \%=0.413 \%$.

TABLE II

COMPARISON OF TRANSFORMERS VALUES FOR R, S, T, Q

\begin{tabular}{|c|c|c|c|}
\hline \multicolumn{4}{|c|}{ Measured results of transformers by IDAX } \\
\hline Autoransfor-mers & $\begin{array}{c}\operatorname{tg} \delta \% \text { at } \\
50 \mathrm{~Hz} / 20^{\circ} \mathrm{C}\end{array}$ & $\begin{array}{c}\text { Moisture in } \\
\text { paper }(\%)\end{array}$ & $\begin{array}{c}\text { Conductivity of } \\
\text { the oil at } \\
25^{\circ} \mathrm{C}(\mathrm{pS} / \mathrm{m}) \\
\end{array}$ \\
\hline $\mathrm{R}$ & 0.323 & 1.9 & 0.43 \\
\hline $\mathrm{S}$ & 0.380 & 2.3 & 3.44 \\
\hline $\mathrm{T}$ & 0.381 & 2.4 & 1.36 \\
\hline Q & 0.413 & 3.0 & 3.28 \\
\hline
\end{tabular}

The insulation state (conductivity) of the oil at $25^{\circ} \mathrm{C}$ of the R, S, T, Q autotransformers was good according to the oil 
conductivity table. Temperature at $25^{\circ} \mathrm{C}$ is standard for investigation and comparison of other transformer oils.

Comparing the analysed transformers, the best (lowest) value of the relative conductivity of the oil was observed in autotransformer R $(0.43 \mathrm{pS} / \mathrm{m})$. Transformers $\mathrm{S}, \mathrm{T}$ and $\mathrm{Q}$ had oil values in the range from $1.36 \mathrm{pS} / \mathrm{m}$ to $3.44 \mathrm{pS} / \mathrm{m}$ (Table II).

The moisture content in the paper in the individual autotransformers R, S, T, Q was different according to the rating table. Comparing all four transformers, the best (lowest) value of the moisture state in the paper was shown by transformer R (1.9\%), which, according to the evaluation table, is dry. Autotransformers $\mathrm{S}$ and $\mathrm{T}$ had approximately the same humidity value $(2.3-2.4 \%)$, which, according to the rating table, is slightly humid. The last autotransformer Q had the highest humidity value ( $3 \%$ ), which, according to the rating table, is the mild to wet boundary between the conditions.

Based on the above-mentioned analysis of the measured values, it is possible to confirm that in autotransformer $\mathrm{T}$, which is currently used as a reserve, most of the moisture is deposited in the paper portion of the insulation. This corresponds to the oil conductivity value of $1.36 \mathrm{pS} / \mathrm{m}$.

From the measured values, it is possible to estimate for autotransformer $\mathrm{T}$ that during operation, the conductivity value of the oil would be higher than that of autotransformers $\mathrm{S}$ and $\mathrm{Q}$, which means that before it is put into full operation, it will be necessary to act to reduce the moisture condition of the isolating system of autotransformer $\mathrm{T}$.

The measurement and then the diagnostics confirm that the transformer oil in autotransformer $\mathrm{R}$ has undergone a total recovery year before measurement. The moisture content and oil conductivity values confirm the excellent state for the power class and the size of the autotransformers to be measured.

A slightly higher oil conductivity value in autotransformer $\mathrm{S}$ may indicate a higher load than that of transformer Q. However, the analysis revealed that the moisture content of transformer Q is the highest among the other measured units, but this also means a higher susceptibility to the overcurrent failure (Fig. 10).

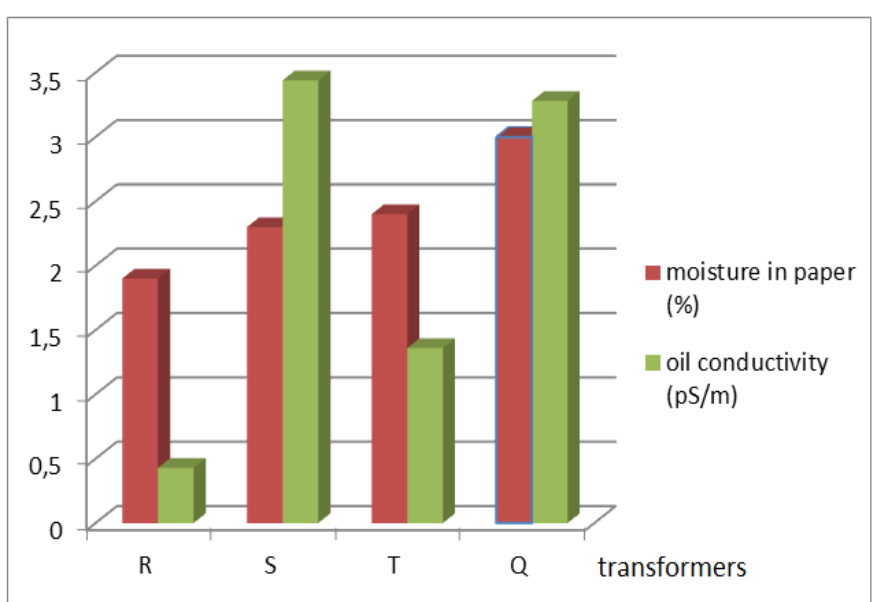

Fig. 10. Comparison of measured autotransformers R, S, T, Q according to the moisture in the paper $(\%)$ and oil conductivity $(\mathrm{pS} / \mathrm{m})$.

\section{CONCLUSION}

In the paper, we present an experiment of analysis of the insulating condition of a high-voltage power transformer using frequency dielectric spectroscopy. The aim was to show that this method may be suitable for diagnostics of the moisture content of the insulating paper and conductivity of the transformer oil.

Experimental measurements have shown a correlation between the measured values and the operational aspects of the individual transformers. It has been shown that the biggest danger for the insulation of oil transformers is their shutdown from operation (the highest moisture content in the paper in transformer Q).

To confirm or disprove the results of spectrum spectroscopy analysis, it would be also useful to analyse the dissolved gas in the oil of the autotransformers measured for the presence of $\mathrm{CO}_{2}$ and $\mathrm{CO}$ gases, the amount of which is mainly influenced by the quality of cellulose and possible leakage of the autotransformer vessel. Despite the accuracy of the measuring device, it would be useful to compare the loss factors with the higher precision measuring instrument.

This experimental analysis is aimed at determination of a new set of diagnostic measuring techniques for the analysis of the state of the selected type of oil filled power transformers.

These goals will be achieved on the basis of complex analysis of the measured values using the measurements implied by the established and new diagnostic methods and techniques, simulated and experimental analysis and electronic equipment [26], [27].

We will also connect physical models describing measurable parameters of the partial discharge process with the effect of the degradation of insulation of oil transformer with the increased originality and the innovation, and on that basis a new integrated system of diagnostics with the possibility of analysis and classification of possible failures on power transformers will be created.

It is expected that it will be possible to identify the location and size of a possible mechanical and insulation failure of the transformer using the measurements discussed

\section{ACKNOWLEDGMENT}

This work was supported by the Grant Agency VEGA from the Ministry of Education of Slovak Republic under contract $1 / 0471 / 20$.

\section{REFERENCES}

[1] M. Bartlomiejczyk, M. Gutten and S. Hamacek, "A Combined TOPSIS and FA Based Strategic Analysis of Technical Condition of High Power Transformers", Advances in Electrical and Electronic Engineering, vol. 11 , no. 4 , 2013, pp. 251-259. https://doi.org/10.15598/aeee.v11i4.863

[2] M. Koch, M. Krueger and M. Puetter, "Advanced Insulation Diagnostic by Dielectric Spectroscopy", Omicron Electronics Austria, 2011.

[3] M. Brandt, "Identification failure of 3 MVA furnace transformer", in: DEMISEE 2016, Proceedings of international conference Diagnostic of electrical machines and insulating systems in electrical engineering, Papradno, Slovakia, 2016. https://doi.org/10.1109/DEMISEE.2016.7530472

[4] M. Simko and M. Chupac, "Non-destructive method of measurement of radio transmitters antenna systems," Electronics and electrical engineering, vol. 107, 2011, pp. 33-36.

[5] J. Petras et al., "Thermally stimulated acoustic energy shift in transformer oil", Acta Acustica United with Acustica, vol. 102, pp. 16-22, 2016. https://doi.org/10.3813/AAA.918920 
[6] M. Rajnak et al., "Structure and viscosity of a transformer oil-based ferrofluid under an external electric field", Journal of Magnetism and Magnetic Materials, vol. 431, 2017, pp. 99-102. https://doi.org/10.1016/j.jmmm.2016.10.008

[7] J. Kanuch, Z. Ferkova, "Simulation stepping motor with DISC rotor", International Conference on Low Voltage Electrical Machines, Brno, 2010.

[8] M. Brandt, "Experimental measurement and analysis of frequency responses SFRA for rotating electrical machines", in Elektroenergetika 2017, Stará Lesná, Slovak Republic, pp. 284-288, 2017.

[9] M. Orman, C. T. Pinto, "Usage of acoustic camera for condition monitoring of electric motors", in IEEE International Conference TENCON, IEEE, 2013. https://doi.org/10.1109/TENCON.2013.6718909

[10] C. Bartoletti et al., "Vibro-acoustic techniques to diagnose power transformers", IEEE Transactions on Power Delivery, vol. 19, no. 1, pp. 221-229, 2004. https://doi.org/10.1109/TPWRD.2003.820177

[11] A. Olszewska, F. Witos, "Identification of Acoustic Emission Signals Originating from the Core Magnetization of Power Oil Transformer", Archives of Acoustics, vol. 41, no. 4, pp. 799-812, 2016. https://doi.org/10.1515/aoa-2016-0077

[12] J. Ramírez-Niño, A. Pascacio, "Acoustic measuring of partial discharge in power transformers", Measurement Science and Technology, vol. 20, no. 11,2009 . https://doi.org/10.1088/0957-0233/20/11/115108

[13] T. Boczar, A. Cichon, S. Borucki, "Diagnostic expert system of transformer insulation systems using the acoustic emission method", IEEE Transactions on Dielectrics and Electrical Insulation, vol. 21, no. 2, pp. 854-865, 2014. https://doi.org/10.1109/TDEI.2013.004126

[14] M. Jin, J. Pan, "Vibration transmission from internal structures to the tank of an oil-filled power transformer", Applied Acoustics, vol. 113, pp. 1-6, 2016. https://doi.org/10.1016/j.apacoust.2016.05.022

[15] B. García, J. C. Burgos, A. M. Alonso, "Transformer tank vibration modeling as a method of detecting winding deformations-part I: theoretical foundation", IEEE Transactions on Power Delivery, vol. 21 , no. 1, pp. 157-169, 2006. https://doi.org/10.1109/TPWRD.2005.852280

[16] M. Zhao et al., "Feature extraction of power transformer vibration signals based on empirical wavelet transform and multiscale entropy", IET Science, Measurement \& Technology, vol. 12, no. 1, pp. 63-71, 2018 https://doi.org/10.1049/iet-smt.2017.0188

[17] M. Koch, S. Tenbohlen, M. Krüger and A. Kraetge, "A Comparative Test and Consequent Improvements on Dielectric Response Methods" Proceedings of the XVth International Symposium on High Voltage Engineering, ISH, Ljubljana, Slovenia, 2007.

[18] M. Koch, "Reliable Moisture Determination in Power Transformers", $\mathrm{PhD}$ thesis, Institute of Energy Transmission and High Voltage Engineering, University of Stuttgart, Sierke Verlag Göttingen, 2008.

[19] M. Gutten, D. Korenciak, M. Kucera, M. Sebok, M. Opielak, P. Zukowski and T. N. Koltunowicz, "Maintenance diagnostics of transformers considering the influence of short-circuit currents during operation," Maintenance and Reliability, vol. 19, no. 3, 2017, pp. 459-466. https://doi.org/10.17531/ein.2017.3.17

[20] C. Kozak, M. Sebok and M. Kucera, "The effect of direct voltage polarity on the value of electric arc burning on the W10 switch contacts," Przeglad elektrotechniczny, vol. 88, 2012, pp. 96-98.

[21] M. Koch and M. Kruger, "Moisture Determination by Improved On-Site Diagnostics", TechCon Asia Pacific, Sydney, 2008.

[22] R. Neimanis, "On Estimation of Moisture Content in Mass Impregnated Distribution Cables," Stockholm: Royal Institute of Technology Stockholm, 2001.
[23] B. Asad, T. Vaimann, A. Rassolkin, A. Kallaste, A. Belahcen, "Review of Electrical Machine Diagnostic Methods Applicability in the Perspective of Industry 4.0," Electrical, Control and Communication Engineering, vol. 14, no. 2, pp. 108-116, 2018.

https://doi.org/10.2478/ecce-2018-0013

[24] B. Asad, T. Vaimann, A. Rassolkin, A. Kallaste, A. Belahcen, "A Survey of Broken Rotor Bar Fault Diagnostic Methods of Induction Motor," Electrical, Control and Communication Engineering, vol. 14, no. 2, pp. 117-124, 2018. https://doi.org/10.2478/ecce-2018-0014

[25] P. Spanik, J. Sedo, P. Drgona, M. Frivaldski, "Real Time Harmonic Analysis of Recuperative Current through Utilization of Digital Measuring Equipment", Elektronika ir Elektronika, vol. 19, no. 5, 2013, pp 33-38. https://doi.org/10.5755/j01.eee.19.5.4364

[26] J. Kudelcik, S. Hardon, L. Varacka, "Measurement of Complex Permittivity of Oil-Based Ferrofluid in Magnetic Field", Acta Physica Polonica A, vol. 131, 2017, pp. 931-933. https://doi.org/10.12693/APhysPolA.131.931

[27] J. Kudelcik, S. P. Bury, S. Hardon, P. Kopcansky, M. Timko "Influence of nanoparticles diameter on structural properties of magnetic fluid in magnetic field", Jornal of Electricla Engineering-Elektrotechnicky casopis, vol. 66, no. 4, 2015, pp. 231-234. https://doi.org/10.2478/jee2015-0037

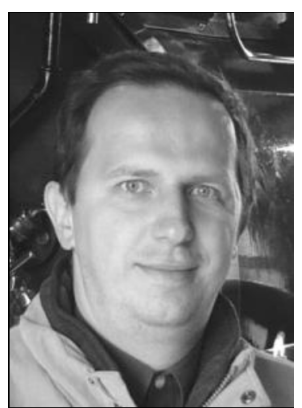

Prof. Miroslav Gutten, Ph. D., University of Zilina. In its scientific and research activities he is for several years dealing with the solution of the project and grant tasks in the area of diagnostics of electrical and electronic equipment (electrical machines, automotive systems, electrical transfer devices, techniques for acoustic emission). Prof. Miroslav Gutten is the head of the research team and the Department of Measurement and Application Electrical Engineering. E-mail: miroslav.gutten@fel.uniza.sk 